\title{
Diclofenac Sodium Loaded Sustained Release Matrix Tablet Possessing Natural and Synthetic Polymers: Formulation and in vitro Characterization
}

\author{
Upendra Nagaich, Charu Bharti ${ }^{\star}$, Ashok Kumar Pal, Neha Gulati. \\ Department of Pharmaceutics, School of Pharmacy, Bharat Institute of Technology, Partapur By Pass Road, Meerut-250103 Uttar \\ Pradesh.
}

\begin{abstract}
Object: The objective of the present study was to investigate the effect of various concentrations of natural and synthetic polymers on in vitro drug release from sustained release matrix tablets. Materials and method: HPMC K4M and acacia gum were used as synthetic (hydrophilic) and natural (hydrophobic) polymers respectively. Diclofenac sodium was used as a model drug to study the in vitro release profile. Matrix tablets of Diclofenac sodium were fabricated by varying the concentrations of both natural and synthetic polymer via direct compression method. Result: The results of all evaluation parameters of the matrix tablet were within the acceptable limit. A significant difference was observed on in vitro drug release due to difference in polymers and their concentration. HPMC $\mathrm{K} 4 \mathrm{M}$ in the concentration of $7 \% \mathrm{w} / \mathrm{v}$ showed $88.20 \pm 0.056 \%$ cumulative drug release at the end of $10 \mathrm{~h}$ while the same concentration of acacia showed $85.22 \% \pm 0.045 \%$. The release mechanism of matrix tablet followed zero order release kinetics. The finding of current investigation clearly indicates that the synthetic polymer was given a more sustained release profile than natural polymer on varied concentration. Conclusion: On comparing in vitro release of optimized formulation with marketed preparation, it was concluded that F3 was found to be more efficient and promising than marketed preparation.
\end{abstract}

Key words: HPMC K4M, Acacia, Matrix Tablet, Diclofenac Sodium, In vitro drug release.

\section{INTRODUCTION}

Oral route is very admired and commodious route of a drug administration. Oral route of administration has been used for both conventional and novel drug delivery system. In the modern era, sustained release dosage form is suppressing the use of conventional dosage form. ${ }^{1}$ The sustained release tablet provides uniform release of drug over a long period of time. Controlled release dosage form covers a wide range of prolonged action formulation which provides continuous release of their active ingredient at a predetermined rate and time. ${ }^{2}$ Sustained or controlled drug delivery system is to reduce the frequency of dosing or to increase the effectiveness of drug by localization at the site of action, reducing dose required, providing continuous drug delivery, reduce incidence of adverse effect and maintain drug concentration in system. ${ }^{1,3}$ Matrix tablets serve as an important tool for oral extended- release dosage forms. Hence, various problems like patient compliance, drug targeting, local side effects, frequent administration and fluctuations in blood concentration levels, associated with their counterparts, therefore the conventional dosage forms restricted. A matrix tablet is the oral solid dosage form in which the drug or active ingredient is homogeneously dispersed throughout the hydrophilic or hydrophobic matrices which serve as release rate retardants. ${ }^{1,4}$ Polymers are high molecular weight compound originate from natural and synthetic source. Hydrophilic polymer (HPMC K4M) basically the cellulose derivative use of matrices, which satisfy the key criteria of release pattern by
Submission Date :02-07-13 Revision Date : :22-09-14 Accepted Date : :06-11-14

DOI: $10.5530 /$ ijper.48.4s.7 Correspondence Address Mr. Charu Bharti

Department of Pharmaceutics Schools of pharmacy, Bharat Institute of Technology, Partapur By pass, Meerut -250103, Uttar Pradesh

Email: Charubhartisdmzn@ gmail.com.

Mobile:09634867115

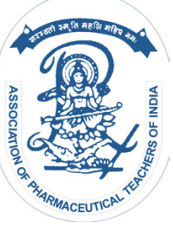

www.ijper.org 
swelling property. HPMC is a partly o-methylated and o-(2-hydroxypropylated) cellulose with a molecular weight 10,000-1, 5000,000. Hydrophobic polymer (acacia gum) reduced the rate and extent of drug release due to reduced porosity of matrix. Acacia is a complex loose aggregate of sugars and hemiacetal. It is an acidic polysaccharide containing D-galactose, L-arabinose, L-rhamanose, D-glucuronic acid with a molecular weight of approximately 240,000-500,000., ${ }^{5,6}$ Both HPMC K4M and acacia gums are cellulose polymer based matrix which forms hydrogel due to simultaneous migration to the matrix. ${ }^{3}$

Diclofenac sodium is 2-[2,6dichlorophenyl-amino] phenyl acetate and soluble in water. It is a Non- Steroidal Anti-Inflammatory Drug (NSAIDs) with analgesic activity. It inhibits PG synthesis and is somewhat COX-2 selective. It is well absorbed orally, 99\% protein bound, metabolized and excreted both in urine and bile. ${ }^{6}$

\section{MATERIALS AND METHOD}

\section{Materials}

Diclofenac sodium was received as a gift sample from Alchem Laboratories, Baddi, India. All other ingredients such as HPMC K4M, Acacia, lactose, magnesium stearate and talc were purchased from Central Drug House $(\mathrm{CDH})$ New Delhi, India. All ingredients used were of analytical grade.

\section{Method}

Sustained release tablets of diclofenac sodium using varying concentration of natural (Acacia) and synthetic (HPMC K4M) polymers were prepared by direct compression method. Other ingredients like lactose was used as diluent, magnesium stearate as lubricant and talc as glidant. All the excipients along with API weighed as shown in Table 1 and passed through sieve no.20. Then, all ingredients were mixed following geometric mixing excluding glidant and lubricant for 15 minutes. $^{7}$ The powder blend was thoroughly mixed with talc and magnesium stearate and compressed into a $400 \mathrm{mg}$ tab- let using a single rotatory punching machine (KI-150, Khera Instruments Ltd. New Delhi, India).

\section{EVALUATION OF SUSTAINED RELEASE MATRIX TABLETS}

\section{Pre-compressional studies of powder blend}

A preformulation study is the first step in sane drug development. All studies which are performed prior to the development of dosage form to reduce error and provide a remunerative data to carry out dosage form development for the treatment of various diseases.

\section{Angle of repose}

It is defined as the angle of heap to the horizontal plane. Angle of repose was determined by using fixed funnel method. Specified amount of powder drug was transferred to the funnel keeping the orifice of the funnel blocked by thumb. ${ }^{8}$ When powder was cleared from funnel then measured its angle of repose.

Angle of repose $(\theta)=\tan ^{-1} \mathrm{~h} / \mathrm{r}$

\section{Bulk density}

It is the ratio of bulk mass of powder to the bulk volume. It is calculated by this formula-

Bulk density $=$ weight of powder bulk/Bulk volume

\section{Tapped density}

It is the ratio of the weight of blend to the minimum volume occupied in measuring cylinder by powder. Measuring cylinder containing the porous mass of powder was tapped using tapped density apparatus. ${ }^{8}$

Tapped density $=$ weight of powder blend/Tapped volume of packing

\section{Compressibility Indices}

\section{Carr's index}

Based on the apparent bulk density and the tapped density, the percentage compressibility of the powder mixture was determined by the following formula. ${ }^{8,9}$

\begin{tabular}{|l|c|c|c|c|c|c|}
\hline \multicolumn{7}{|c|}{ Table 1: Formulation table of matrix tablet for $\mathbf{4 0 0}$ mg } \\
\hline $\begin{array}{l}\text { Ingredients } \\
\text { (mg) }\end{array}$ & F1 & F2 & F3 & F4 & F5 & F6 \\
\hline $\begin{array}{l}\text { Diclofenac } \\
\text { sodium }\end{array}$ & 50 & 50 & 50 & 50 & 50 & 50 \\
\hline HPMC(K4M) & 12 & 20 & 28 & - & - & - \\
\hline Acacia & - & - & - & 12 & 320 & 28 \\
\hline Lactose & 328 & 320 & 312 & 512 & 5 \\
\hline Talc & 5 & 5 & 5 & 5 & 5 & 5 \\
\hline $\begin{array}{l}\text { Magnesium } \\
\text { stearate }\end{array}$ & 5 & 5 & 5 & & 5 & 5 \\
\hline
\end{tabular}


Carr's index $=\frac{\text { Tapped density-Bulk density }}{\text { Tapped Density }} \times 100$

\section{Hausner's ratio}

It is an indirect index of ease of measuring of powder flow. Lower Hausner's ratio $(<1.25)$ indicates better flow properties than higher ones $(>1.25)$.

Hausner's ratio $=\frac{\text { Tapped density }}{\text { Bulk density }}$

\section{POST-COMPRESSIONAL STUDIES OF PREPARED MATRIX TABLETS}

The matrix tablets were evaluated for appearance, thickness, weight variation, hardness and friability. All the evaluation parameters of all formulations are given in (Table 2).

\section{Physical Appearance}

The general appearance and urbanity of tablet were studied visually. The tablet was round in shape, unstained in color, smooth texture, and odorless.

\section{Thickness}

The tablet thickness was calculated by Vernier calipers. Tablet was put in between two jaws vertically and measured thickness. It is expressed in $\mathrm{mm} .{ }^{8,9}$

\section{Weight variation}

The weight of 20 tablets was measured and average weight was calculated. The individual weight of each tablet was measured to determine its variation. Weight variation was determined by comparison of individual tablet weight with average weight. ${ }^{8,9}$

\section{Hardness}

The tablet hardness was determined by Monsanto hardness tester. The tablet was fitted lengthwise between plunger and force applied. Noted down the pressure at which tablet was crushed. It is measured in $\mathrm{Kg} / \mathrm{cm}^{2} .6$ tablets were used for this study. ${ }^{3}$

\section{Friability}

It is calculated by Roche friability apparatus. Preweighed six tablets were subjected to the device which provided combined effect of shock and abrasion from height of six inches with each rotation, at $25 \mathrm{rpm}$ speed and operated for 100 revolutions. Tablets were dusted and re-weighed. ${ }^{9,10}$ Compressed tablets that lose less than $0.5-1.0 \%$ of their weight were generally considered acceptable. It is expressed in percentage (\%) and calculated by the following formula:

$$
\text { Friability }(\%)=\frac{\text { Initial weight-Final weight }}{\text { Initial weight }} \times 100
$$

\section{Drug Content Uniformity}

The prepared formulation of Diclofenac sodium was weight and crushed. Powder equivalent to $50 \mathrm{mg}$ of diclofenc sodium was weighed and shaken with $10 \mathrm{ml}$ of methanol in $100 \mathrm{ml}$ volumetric flask and filtered. The aliquot $(1 \mathrm{ml})$ was taken and make up its volume up to $100 \mathrm{ml}$ with methanol and absorbance was taken at 285 nm using UV spectrophotometer (UV- 1601, Shimadzu, Japan). Drug content was determined by using standard curve of diclofenac sodium. ${ }^{6,10}$

\section{In vitro drug release study}

In vitro drug release studies were carried out using USP type II (paddle type) apparatus (Lab India Dissolution apparatus D5 8000). Dissolution medium was $900 \mathrm{ml}$ phosphate buffer saline ( $\mathrm{pH}$ 6.8) with paddle rotation at $75 \mathrm{rpm}$ and temperature was maintained at $37 \pm 1{ }^{\circ} \mathrm{C}$. Aliquots of $5 \mathrm{ml}$ were withdrawn after each hour and equivalent amount of fresh buffer maintained at same temperature was replaced to maintain sink conditions. ${ }^{6}$ The samples were analyzed for diclofenac sodium content at $276 \mathrm{~nm}$ by UV-spectrophotometer and calculated the drug release using calibration curve of diclofenac sodium.

\section{In vitro drug release kinetics}

Mechanism of drug release from the matrix tablets using different concentration of natural and synthetic polymer can be studied using different mathematical

Table 2: Micrometrics properties of pre-compressional powder blend

\begin{tabular}{|c|c|c|c|c|}
\hline Formulation code & Angle of repose $(\boldsymbol{\theta})$ & Bulk density $(\mathbf{g} / \mathbf{m l})$ & $\begin{array}{c}\text { Tapped density } \\
(\mathbf{g} / \mathbf{m l})\end{array}$ & Carr's index \\
\hline F1 & $33.41 \pm 0.21$ & $0.4889 \pm 0.22$ & $0.4814 \pm 0.22$ & $17.82 \pm 0.09$ \\
\hline F2 & $30.24 \pm 0.20$ & $0.4279 \pm 0.05$ & $0.4554 \pm 0.11$ & $16.81 \pm 0.08$ \\
\hline F3 & $21.22 \pm 0.11$ & $0.3861 \pm 0.21$ & $0.4281 \pm 0.05$ & $12.09 \pm 0.04$ \\
\hline F4 & $34.22 \pm 0.22$ & $0.4047 \pm 0.03$ & $0.4462 \pm 0.21$ & $13.02 \pm 0.11$ \\
\hline F5 & $29.11 \pm 0.10$ & $0.4147 \pm 0.05$ & $0.4782 \pm 0.34$ & $1.14 \pm 0.06$ \\
\hline F6 & $30.22 \pm 0.65$ & $0.4035 \pm 0.23$ & $0.4841 \pm 0.06$ & $1.01 \pm 0.10$ \\
\hline
\end{tabular}


expressions. The kinetic drug-release data were analyzed according to zero order, first order, Higuchi square root, Kosmeyer-Peppas. The appropriate equation was chosen on the basis of goodness of fit test. ${ }^{3,11}$

\section{RESULTS}

\section{Pre compression parameters}

The prepared formulations were evaluated for pre compression parameters and their results were given in table 2 and 3. The powder blend was evaluated for various parameters like angle of repose, tapped density, bulk density, Carr's index and Hausner's ratio respectively. The value of angle of repose of all formulations ranges between $21.22 \pm 0.11$ to $34.22 \pm 0.22(\theta)$ which shows very good powder flow property. The result of bulk density and tapped density ranges from $0.3861 \pm 0.21$ to $0.4889 \pm 0.22 \mathrm{~g} / \mathrm{ml}$ and $0.4281 \pm 0.05$ to $0.4841 \pm 0.06$ $\mathrm{g} / \mathrm{ml}$ respectively. The values of compressibility indices, including Carr's index and Hausner's ratio ranged from $12.09 \pm 0.04$ to $17.82 \pm 0.09$ and $1.12 \pm 0.09$ to $1.20 \pm$ 0.09 respectively.

\section{Post compression parameters}

The weight of diclofenac loaded matrix tablets was found to be in the range of $0.389 \pm 0.004$ to $0.399 \pm$ $0.002 \mathrm{gm}$. Thickness was observed as $1.2 \pm 0.1 \mathrm{~mm}$ and $\%$ friability of various formulations was found to be in between $0.06 \pm 0.009$ to $0.81 \pm 0.011$. The hardness of tablet was found to be $5.5 \pm 0.2$ to $7.2 \pm 0.2 \mathrm{~kg} / \mathrm{cm}^{2}$. The in vitro drug release that was performed for HPMC and acacia containing formulations were given in figure 2. The $\%$ in vitro drug release from formulations F1, F2, F3, F4, F5 and F6 at the end of $10 \mathrm{~h}$ was found to be $79.22 \pm 0.032 \%, 83.22 \pm 0.01 \%, 88.20 \pm 0.056 \%$, $77.00 \pm 0.013 \%, 81.02 \pm 0.067 \%$ and $85.22 \pm 0.045 \%$ respectively. Drug release kinetics parameters with n, R2 value are provided in (Table 4). The regression coefficient value of zero order was observed R2 value 0.949 to 0.994 . So, the drug release was found to be zero order kinetics.

\section{DISCUSSION}

\section{Pre-compression study of powder blend}

The powder blend was evaluated for various parameters as shown in (Table 2). This showed that powder blend from all the formulations showing good flow property according to standard values. ${ }^{8}$

\section{Post-compression studies of prepared matrix tablets}

The results of post compression evaluation parameters are given in (Table 3), and its description given below.

\section{Thickness}

The determined thickness according to the die and punches size of all formulation was found to be $1.2 \pm$ $0.001 \mathrm{~mm}$. It was upon the die and punch size during compression of tablets and their total weight.

\section{Weight Variation}

The determined weight variation of formulating tablets was found to be in the range of $0.397 \pm 0.005$ to 0.399

\begin{tabular}{|c|c|c|c|c|c|}
\hline \multicolumn{5}{|c|}{ Table 3: Post-compressional studies of Diclofenac loaded matrix tablets. } \\
\hline Formulation code & Weight variation & Hardness $\mathbf{( k g / \mathbf { c m } ^ { 2 } )}$ & Thickness $\mathbf{( m m )}$ & \% Friability & \% Drug release \\
\hline F1 & $0.389 \pm 0.004$ & $5.5 \pm 0.2$ & $1.2 \pm 0.1$ & $0.12 \pm 0.002$ & $79.22 \pm 0.032$ \\
\hline F2 & $0.397 \pm 0.005$ & $6.0 \pm 0.3$ & $1.2 \pm 0.1$ & $0.28 \pm 0.08$ & $83.22 \pm 0.012$ \\
\hline F3 & $0.399 \pm 0.002$ & $7.2 \pm 0.2$ & $1.2 \pm 0.1$ & $0.06 \pm 0.009$ & $88.20 \pm 0.056$ \\
\hline F4 & $0.396 \pm 0.005$ & $5.8 \pm 0.2$ & $1.2 \pm 0.1$ & $0.81 \pm 0.011$ & $77.00 \pm 0.013$ \\
\hline F5 & $0.397 \pm 0.004$ & $6.2 \pm 0.3$ & $1.2 \pm 0.1$ & $0.69 \pm 0.018$ & $81.02 \pm 0.067$ \\
\hline F6 & $0.398 \pm 0.003$ & $6.8 \pm 0.2$ & $1.2 \pm 0.1$ & $0.38 \pm 0.032$ & $85.22 \pm 0.045$ \\
\hline
\end{tabular}

\begin{tabular}{|c|c|c|c|c|c|}
\hline \multicolumn{2}{|c|}{ Table 4: Release kinetics profile of Diclofenac loaded sodium matrix tablets. } \\
\hline Formulation code & Zero order (R2) & First order (R2) & Higuchi (R2) & $\begin{array}{c}\text { Korsmeyer peppas } \\
\text { (R2) }\end{array}$ & Value of (n) \\
\hline F1 & 0.9746 & 0.6231 & 0.9749 & 0.7080 & 1.100 \\
\hline F2 & 0.9925 & 0.6460 & 0.9880 & 0.7408 & 1.299 \\
\hline F3 & 0.9954 & 0.7247 & 0.9347 & 0.7644 & 1.159 \\
\hline F4 & 0.949 & 0.6023 & 0.9897 & 0.6384 & 1.008 \\
\hline F5 & 0.9807 & 0.6813 & 0.9755 & 0.6901 & 1.073 \\
\hline F6 & 0.9947 & 0.7186 & 0.9518 & 0.7474 & 1.134 \\
\hline Marketed & 0.9951 & 0.7268 & 0.9401 & 0.7589 & 1.142 \\
\hline
\end{tabular}




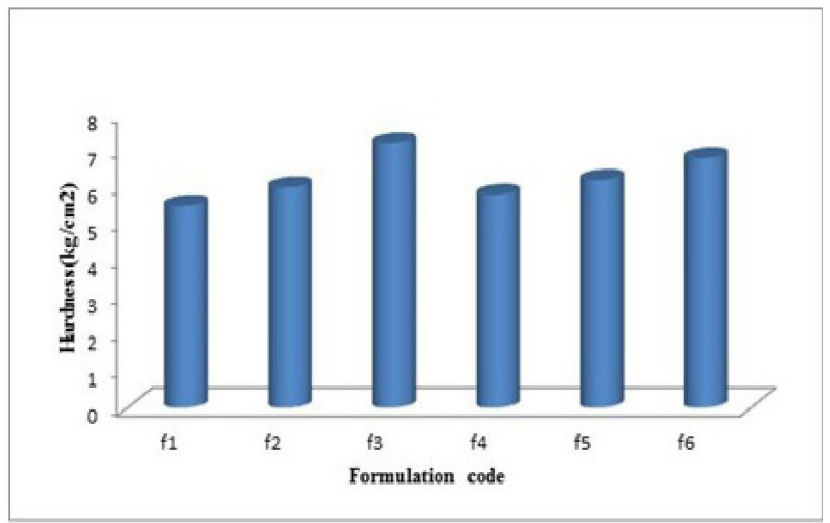

Figure 1: Graph illustrating the hardness profile of different sustained release formulations

\pm 0.002 . It was found to be within pharmacopeias limit of $\pm 5 \%$ as per I.P. ${ }^{10}$

\section{Hardness}

The hardness of tablet $(n=3)$ of formulation code F1, F2, F3, F4, F5, F6 which was given satisfactory result as per standard. On increasing the concentration of polymer hardness was also increases gradually. Since, high concentration of synthetic polymer enhanced more hardness than natural polymer. ${ }^{12}$ The variation of hardness in various formulation codes was shown in (Figure. 1).

\section{$\%$ Friability}

The result of friability was found to be $0.06 \pm 0.002$ to $0.81 \pm 0.032$, which was less than $1 \%$ as per the pharmacopeias limit. Highest concentrations of polymers in matrix tablet also affect the friability. It showed that tablets have sufficient strength to tolerate transportation stress. $^{13,14}$

\section{In vitro Drug Release Study}

The in vitro drug release was carried out in phosphate buffer of $\mathrm{pH}$ 6.8. The initial drug release was depending upon the water penetration in to the polymeric matrix. The formulations F1 to F6 were given sustained drug release profile for $10 \mathrm{~h}$ study as $79.22 \pm 0.032 \%, 83.22$ $\pm 0.012 \%, 88.20 \pm 0.056 \%, 77.00 \pm 0.013 \%, 81.02 \pm$ $0.067 \%$ and $85.22 \pm 0.045 \%$ respectively. The optimized formulation profile was given by F3 contained $7 \%$ concentration of HPMC K4M act as hydrophilic rate retardant property. This indicated that synthetic

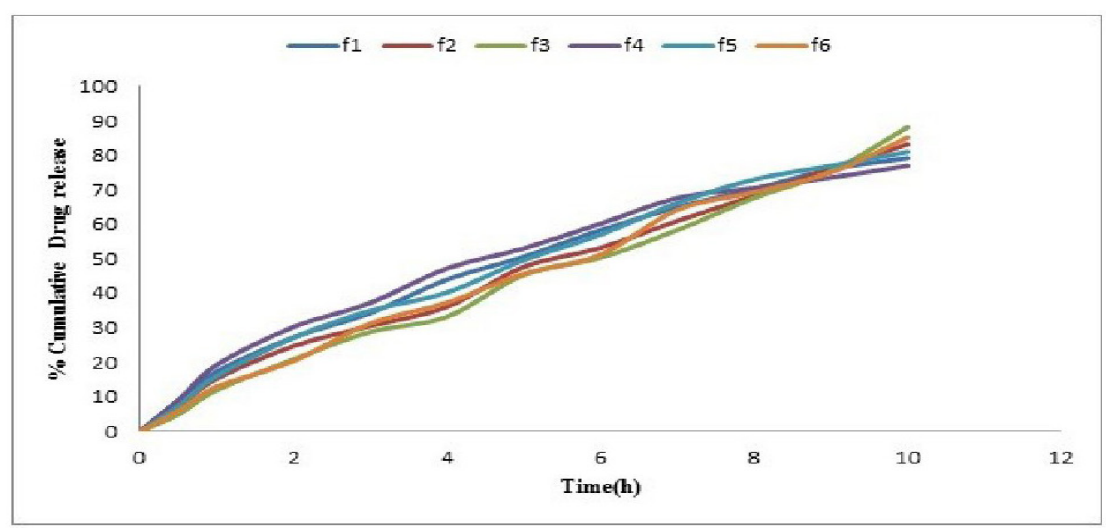

Figure 2: In vitro drug release profile of Diclofenac sodium containing matrix tablets for all formulations

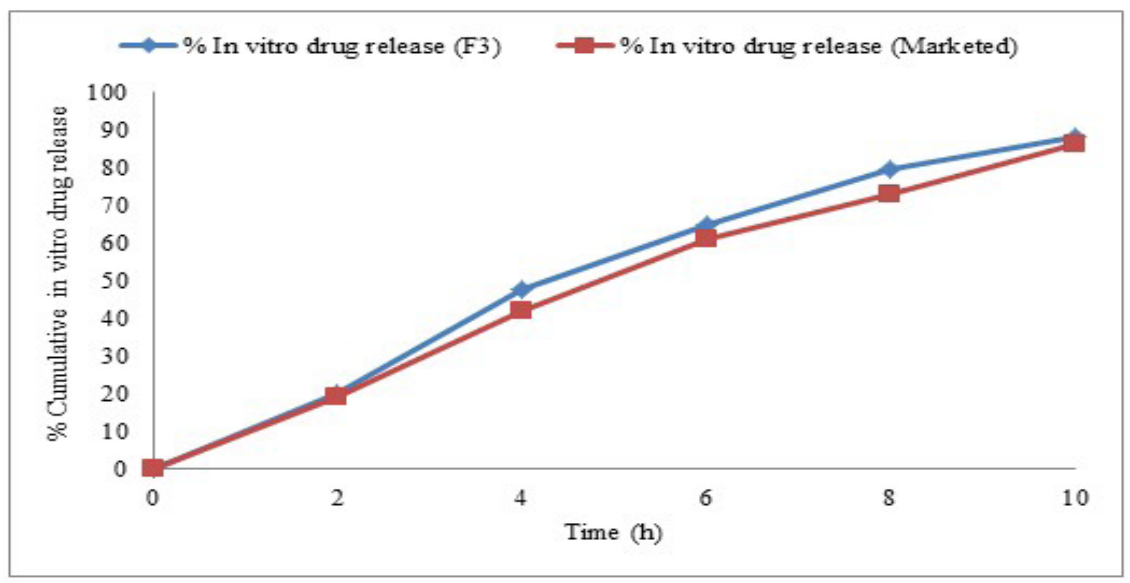

Figure 3: \% Comparative In vitro drug release of optimised formulation F3 and marketed preparation 


\begin{tabular}{|c|c|c|c|c|c|c|}
\hline \multirow{2}{*}{ Days } & \multicolumn{5}{|c|}{ Optimized Formulation (F3) } \\
\cline { 2 - 7 } & \multicolumn{3}{|c|}{ Physical appearance } \\
\cline { 2 - 7 } & RT & FT Stability Studies at different Temperature for the Formulation F3 \\
\hline $\mathbf{0}$ & + & + & AT & RT & FT & AT \\
\hline $\mathbf{7}$ & + & + & + & $88.20 \pm 0.056$ & $88.20 \pm 0.056$ & $88.20 \pm 0.056$ \\
\hline $\mathbf{1 4}$ & + & + & + & $88.17 \pm 0.20$ & $88.12 \pm 0.44$ & $88.16 \pm 0.19$ \\
\hline $\mathbf{2 8}$ & + & + & + & $88.09 \pm 0.11$ & $88.07 \pm 0.79$ & $88.04 \pm 0.34$ \\
\hline $\mathbf{3 5}$ & + & + & + & $88.01 \pm 0.02$ & $87.84 \pm 0.56$ & $87.80 \pm 0.06$ \\
\hline $\mathbf{4 5}$ & + & + & ++ & $87.72 \pm 0.13$ & $87.11 \pm 0.37$ & $87.42 \pm 0.36$ \\
\hline $\mathbf{6 0}$ & + & ++ & ++ & $87.28 \pm 0.05$ & $86.89 \pm 0.28$ & $86.78 \pm 0.01$ \\
\hline
\end{tabular}

polymer have more release retardant property than natural polymer. Availability of sufficient time for swelling and gelling was responsible for the slow release of drug. ${ }^{15}$ The viscosity of HPMC K4M was more than the acacia so; it was showing better result in matrix tablet. And the hydration rate of HPMC depends on the nature of the substituents like hydroxypropyl group content. Hence, HPMC K4M was formed a strong viscous gel in contact with aqueous media which may be useful in controlled delivery of drug than natural polymer. ${ }^{5,7}$ The comparative in vitro drug release of optimized formulation and marketed formulation was given in (Figure 3).

\section{In vitro Drug Release Kinetics}

The release kinetics model was used for the goodness of fit by linear regression analysis with the help of zero order, first order, Higuchi's and korsmeyer peppas equation in order to determine release and mechanism of drug action. The regression coefficient value of zero order was observed $\mathrm{R}^{2}$ value 0.949 to 0.994 . So, the drug release was found to be zero order kinetics. The first order equation depends upon the Noyes Whitney equation. Higuchi describes release of drug from insoluble matrix as the square root $\mathrm{t}$ dependent release and $\mathrm{R}^{2}$ value was found to be 0.934 to 0.9897 . Korsmeyer peppas describe the mechanism of drug release was found to be non-fickian super case II. ${ }^{15}$ The observations of release kinetics of all fabricated and marketed formulations are shown in (Table 4).

\section{Stability Studies}

Stability studies were performed for optimized formulation and marketed formulation at various temperature conditions as room temperature $(\mathrm{RT}=30 \pm$ $5^{0}$ ), freezing temperature ( $\mathrm{FT}=2-4 \pm 2^{0}$ ), and accelerated temperature $\left(\mathrm{AT}=45 \pm 5^{\circ}\right)$ for 60 days. For F3 slight colour change was seen after 45 days at accelerated condition, but no further defects were seen till 60 days. ${ }^{16,17}$ Marketed preparation was also tested for stability in similar conditions for 60 days. After 45 days slight colour change was observed at room temperature and accelerated conditions. And mottling was also observed after 60 days at accelerated conditions. The stability studies of optimized and marketed preparation were showed in (Table 5, 6).

\section{CONCLUSION}

From the above study, it was estimated that the synthetic polymer exhibit release over a long period of

\begin{tabular}{|c|c|c|c|c|c|c|}
\hline \multirow{2}{*}{ Days } & \multicolumn{9}{|c|}{ Marketed } \\
\cline { 2 - 7 } & \multicolumn{3}{|c|}{ Physical appearance } & \multicolumn{4}{c|}{ Drug content (\%) } \\
\cline { 2 - 7 } & RT & FT & AT & RT & FT & AT \\
\hline $\mathbf{0}$ & + & + & + & $86.17 \pm 0.12$ & $86.17 \pm 0.12$ & $86.17 \pm 0.12$ \\
\hline $\mathbf{7}$ & + & + & + & $86.17 \pm 0.17$ & $86.17 \pm 0.18$ & $86.17 \pm 0.61$ \\
\hline $\mathbf{1 4}$ & + & + & + & $86.14 \pm 0.11$ & $86.03 \pm 0.44$ & $86.06 \pm 0.29$ \\
\hline $\mathbf{2 8}$ & + & + & ++ & $86.02 \pm 0.32$ & $85.99 \pm 0.19$ & $85.64 \pm 0.24$ \\
\hline $\mathbf{3 5}$ & + & + & ++ & $85.77 \pm 0.91$ & $85.24 \pm 0.66$ & $85.87 \pm 0.01$ \\
\hline $\mathbf{4 5}$ & + & ++ & ++ & $85.39 \pm 0.15$ & $85.21 \pm 0.17$ & $85.53 \pm 0.11$ \\
\hline $\mathbf{6 0}$ & ++ & - & - & $85.78 \pm 0.01$ & $84.88 \pm 0.28$ & $84.46 \pm 0.02$ \\
\hline
\end{tabular}


time than natural polymer. All characterized parameters of drug were found to be within the satisfactory limit. The drug polymer ratio was found to influence the drug release, as the polymer level increased, the drug release rates were found to be decreased. The release of drug after a study of the release kinetics model follows zero order and the mechanism of drug release was found to be non- fickian diffusion super case II. Concentration of natural and synthetic polymer also affects the hardness and drug release profile. Amongst different formulations, F3 (HPMC) was found to be an optimized formulation which gives better results than the marketed formulation on the basis of in vitro release. Thus, it can be concluded that the formulation F3 can be more efficient and potential in comparison with marketed formulation for the development of sustained drug delivery system.

\section{CONFLICT OF INTERESTS}

The authors report no conflict of interests.

\section{ACKNOWLEDGEMENT}

I am very thankful to Alchem Laboratories, Baddi, India for providing the gift sample of Diclofenac sodium. I am also thankful to the worthy faculty members of the pharmaceutics department of Bharat Institute of Technology, Meerut, India for providing the necessary facilities to carry out this research work.

\section{REFERENCES}

1. Dash RT, Verma P. Matrix: An approach towards oral extended release drug delivery. IJPPR. 2012; 2(2): 12-24.

2. Akhtar MF, Rabbani M. et al. Formulation and Characterization of Modified Release Tablets Containing Isoniazid Using Swellable Polymers. Afr J Tradit Complement Altern Med. 2011; 8(3): 250-9.

3. Fulbandhe VM, Jobanputra $C R$, et al. Evaluation of release retarding property of gum damar and gum copal in combination with HPMC. IJPS. 2012; 74(3): 189-94.

4. Gilbert's B, Christopher R. Modern pharmaceutics. $4^{\text {th }}$ ed. Marell Dekker; 1996: 503-13.

5. Thakkar V, Shaikh V, Soni T, Gandhi T. Design and evaluation of sustained release enteric coated dosage form of fluoxetine hydrochloride. IJPER. 2012; 46(4): 330-9.

6. Kumar MV, Harani VA, Padmasri S, Kartika D, Chandra M. Formulation and evaluation of sustained release hydrophilic matrix tablet of diclofenac sodium using natural gum. Inventi rapid. 2012; 1087-94.

7. Emami J, Tajeddin M, Ahmadi F. Preparation and In vitro Evaluation of Sustained-Release Matrix Tablets of Flutamide Using Synthetic and Naturally Occurring Polymers. IJPR. 2008; 7(4): 247-57.

8. Aulton ME. Pharmaceutics - The science of dosage form design, 2nd edition; 2013. 360-461.

9. Lachman L, Lieberman HA, Kanig JL. The theory and practice of industrial pharmacy. $3^{\text {rd }}$ ed.Varghese publishing house; 1991. 67-71.

10. Indian Pharmacopoeia: Ministry of Health and Family Welfare, Government of India. Published by The Indian Pharmacopoeial commission: Ghaziabad. 2010; I(II): 193, 751-3, 1199.
11. Mohammad RSS, Addo KA, et al. Release behavior of propranolol from hydrophilic matrix tablets containing psyllium powder in combination with hydrophilic polymer. AAPS Pharm Sci Tech. 2011; 12(4): 1176-82.

12. Mehta $R$, Chawla $A$, et al. Formulation and in vitro evaluation of Eudragit S-100 coated naproxen matrix tablets for colon-targeted drug delivery system. J Adv Pharm Tech Res. 2013; 4(1): 31-41.

13. Patel $\mathrm{N}$, Thakurs $\mathrm{R}$, et al. Formulation and evaluation of controlled release matrix tablet of a model antibiotic drug. AJPTR. 2012; 12(2): 681-94.

14. Balogue $E$, Semjigit T. Design and evaluation of layered matrix tablet formulation of metaprolol tartarate. APPS Pharm SciTech. 2010; 11(2): 563-73.

15. Bravo SA, Lamas MC, Salmon CJ. In-vitro study of diclofenac sodium controlled release from biopolymeric matrices. J Pharm Sci. 2002; 5(3): 213-9.

16. Mandal S, Basu SK, Sa B. Sustained Release of a Water-Soluble Drug from Alginate Matrix Tablets Prepared by Wet Granulation Method. AAPS Pharm Sci Tech. 2009; 10(4): 1348-56.

17. Malviya R, Srivastava P, Bansal M, Sharma PK. Formulation and Optimization of Sustained Release Tablets of Diclofenac Sodium Using Guar Gum as Release Modifier. Int J Pharm Sci Res. 2010; 1: 82-8. 